\title{
A Study on the Trends of Fin Tech
}

\author{
Young-mo kang ${ }^{1}$, Kyeong-seok Han ${ }^{2}$, Se-Jeong Park ${ }^{3}$ and Jong-Bae Kim ${ }^{4 *}$ \\ ${ }^{1,2}$ Department of IT policy \& management, Soongsil University, Seoul, \\ 156-743, Korea \\ ${ }^{3,4}$ Graduate School of Software, Soongsil University, Seoul 156-743, Korea \\ ${ }^{1}$ cnn5001kr@naver.com, ${ }^{2} k s h a n @ s s u . a c . k r,{ }^{3}$ sejung90@naver.com, \\ 4*kjb123@ssu.ac.kr
}

\begin{abstract}
The financially reputed, global financial powerhouses, such as the United Kingdom, Germany, China, etc, have invested more than \$3,000 million in fintech worldwide. Fintech, so called 'financial tech,' is a portmanteau of 'finance' and 'technology,' referring to the financial service where various techniques have been introduced, such as bank transfer, personal finance asset management, crowdfunding, and mobile payments.

A global financial hub, the United Kingdom, is emerging as a center of fin-tech startups, where investments are concentrated. Recently, approximately $\$ 800$ million of investments have been intensively made in fin-tech start-ups of the UK and Ireland, showing more than $600 \%$ in a growth rate. Cash transactions account for nearly $85 \%$ worldwide, so the credit card fee market seems yet to be a highly potential market. Given the credit card industry has earned about $\$ 48$ billion of fees last year, it is predicted that enterprises' desire for the fee market innovation will much change. For fin-tech, security is a prerequisite. It is because if security is not guaranteed, no one knows what security threat will occur. Fin-tech is just like a double-edged sword it's easy access but security must be guaranteed for users at the same time. Thus, it is necessary to blend convenience and security. The reality is that changes in the financial environment are made clearly. In addition, with the specialization and diversification of financial needs, it will be required to devise the thing that will meet the needs for new financial services from a number of customers and prosumers.
\end{abstract}

Keywords: Fin-tech, Financial Settlement, Affirm, PCI DSS, Phishing

\section{Introduction}

Recently, there is an increasing interest in fin-tech, financial tech. FinTech is a combined word of financial and technology, through a combination of financial and ICT, which means the emerging industrial and service sectors. In fact finTech has, since the sub-prime loan problems that have occurred in the United States in 2007, spread to the global financial crisis of 2008. The consumers start to distrust the existing financial industry when a circumstance happened and it did not respond quickly in the economic crisis. The emergence of rapidly developing ICT technology has been replaced by a service that existing financial industry was in charge of the new platform. As the fin-tech market is growing fast, Korea also appears to have a continuous interest in fin-tech through its government and financial institutions and to be ready for the activation for the growth of fin-tech [1]. The chairperson of the Financial Services Commission also put an emphasis on the importance of fin-tech in the financial development council saying that it is necessary to find a new opportunity for the domestic banking industry to grow in a new trend fin-tech. In addition, many financial institutions in Korea also mentioned about the

Corresponding Author 
creation of the condition that fin-tech can be activated. With regard to this, research materials appeared one after another [11]. Therefore, this study tried to investigate fintech and to explain about trends and characteristics of fin-tech in each financial powerhouse. It also attempted to analyze the outlook about fin-tech in the Korean market of the future.

Table 1. Online Payment Service

\begin{tabular}{|c|c|c|}
\hline \multirow{2}{*}{$\begin{array}{c}\text { Online } \\
\text { Payment } \\
\text { Services }\end{array}$} & Alibaba & Alipay \\
\cline { 2 - 3 } & Tencent & Paypal \\
\cline { 2 - 3 } & Amazon & $\begin{array}{c}\text { Amazon } \\
\text { Payment }\end{array}$ \\
\cline { 2 - 3 } & Google & Goole Wallet \\
\hline \multirow{2}{*}{$\begin{array}{c}\text { E-wallet } \\
\text { Services }\end{array}$} & Apple & Passbook \\
\cline { 2 - 3 } & BNP Paribas & Hello Bank \\
\hline \multirow{2}{*}{$\begin{array}{l}\text { Online } \\
\text { Banks }\end{array}$} & Sony & Sony Finance \\
\cline { 2 - 3 } & &
\end{tabular}

\section{Definition of Fin-Tech}

Fin-tech, so called 'financial tech,' is a combined word of 'financial' and 'technology,' referring to the financial services where various technologies have been newly introduced, such as bank transfer, personal financial asset management, mobile payment, etc

In detailed description, it can be represented as the technology (Technology) for banking. People have been forced to suffer a lot of inconvenience for using financial services [13-14]. In case of purchasing goods via the internet, they lost tens of minutes as they had to download active Xs that are constantly repeated. For interpersonal transactions offline, they had to exchange goods in cash by setting a fixed place and time. When they transfer foreign currency to another person residing abroad, we have been forced to suffer lots of losses and discomforts. It is natural that fin-tech began to attract attention as the technology armed with convenience. In fact, before the term 'fin-tech' appeared, previous attempts to transform uncomfortable finance into a comfortable one had been made several times [15]. Such an attempt to transform is the launching of the barcode payment in March 2011, the first in the industry. 
Fin-tech corresponds to a financial process including technical courses to manufacture the software relating to financial services and to increase operational capabilities. In addition, financial tech, i.e. fin-tech, collectively refers to the techniques that may affect the entire business of the financial institution. Due to dissemination of smart devices and development of technologies [7-12]. Changes in and demands from financial consumers have become more specialized [5-6]. Thus, the development of fin-tech has been further facilitated. Especially, according to a number of recent researches on financial markets, fin tech is expected to ensure that the paradigm for the financial intermediation function as the unique function of the existing financial industry will grow into the convergence trend [16].

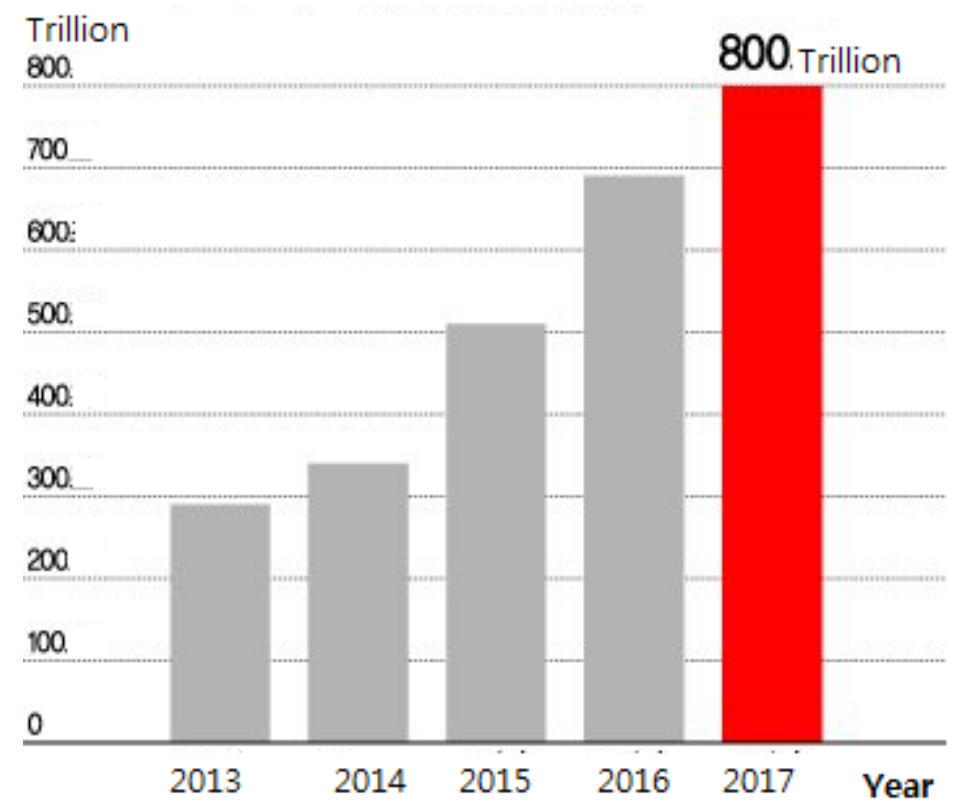

Figure 1. Global Fin Tech Market

\section{Typical Types of Fin-Tech}

The detection method of FDS can be shortly summarized as issuing an alert when a financial transaction breaks the bound of a pattern [8-9]. FDS methods include Rule Method that applies several patterns and Score Method that standardizes ordinary financial transaction patterns on a daily basis and quantifies the correction between the patterns with the patterns of illegal transactions, which results in scores [2-4].

To apply Rule Method, it is important to find abnormal financial transaction patterns out of the types of domestic financial accidents and service threat scenarios and to create detection patterns by using information of users' medium environment transaction types together. This detection model with simply more than two rules whose scopes are set can screen fraud, but it is likely to end up in false positive error unless the two rule variables are not correlated with each other. Therefore, correlation analysis is necessary to apply to this model on the basis of the history of more than two variables. It can optimize the balance between fraud detection and false positive error [10].

Score Method sets the normal pattern boundaries for user's collected information (ID), integrate information of device and set patterns and sets the score range of normal pattern within (1 100) and considers the transactions not included in the normal range as abnormal transactions and detects them. 


\section{Trends and Growth of Fin-Tech}

Each country has made various support policies to use fin-tech innovation as the catalyst for the development of financial industry and as the new power of the economic growth. UK, Australia, Singapore, Hong Kong, etc have supported fin-tech innovation as a global financial hub strategy.

The United Kingdom, a global financial hub, has emerged as a center of fin-tech startups. Recently, $\$ 0.8$ billion of investments have been intensively made in fin-tech start-up of the United Kingdom and Ireland. This has recorded over a $600 \%$ growth rate. In particular, recently the global pin-tech investment has grown into a large scale between 56 years. An Accenture report shows the foreign investment in the main business sector of fin-tech has increased by $\$ 3$ billion in 2013 from about $\$ 0.9$ billion in 2008 .

As the investment of the fin-tech is increasing at a faster rate, the banks of the major overseas are also anxious to take more proactive measures, such as self-survival or acquisitions of IT companies or partnerships with the companies.

The world's leading financial firms are quickly preparing by promoting cooperation with fin-tech companies and, internet-specialized banks to provide financial services fused with new technology. Especially, major banks of Germany, France, etc have provided their own financial services using fin-tech. China is also preparing financial services beyond the functions as a bank as IT companies have created private banks.

As such, this global fin-tech has been activated. However, Korea is very slow in the growth of fin-tech and has not supported fin-tech in systemic aspects as well. Thus, for the growth of fin-tech, it seems that there are many to be improved.

\section{Main Global Promotions of Fin-Tech}

In Germany, Fidor Bank has been providing financial services using its internet site, Facebook, YouTube, Twitter, Google, etc without offline branches. The benefit of the Fidor Bank is a community bank in which clients directly participate. On the internet site of Fidor Bank, a variety of opinions, such as ideas on financial instruments, ratings on financial services, etc are posted.

In addition, for a deposit interest rate, a scheme has been introduced that if the number of Good's, as in Facebook, the deposit interest rate can also rise. Additionally, if a customer offers a financial product and it is selected, a bonus of $€ 100$ is offered to the customer.

In England as a fin-tech hub, the investment in fin-tech almost reaches 0.3 billion in 2013 only. The reason why the United Kingdom has rapidly grown in fin-tech is that the UK government has given its support as much as it could. The British government has assisted in support for start-ups with professional research institutes to take advantage of the fin-tech sector actively.

In China, China's largest e-commerce company, Alibaba, has operated Alipay for payment services and Alifinance for small-sum loan services. In addition, China's largest portal company, Baidu. And one of China's SNS companies, Tencent, started operating payment services. As such, Chinese companies have actively participated with the Chinese government's help with IT companies' expansion to finance business and have operated fin-tech well as an active new growth engine.

\section{Noteworthy Global Fin-Tech Start-Up}

Simple (simple.com) - It is the Simple bank that has been devised against the expensive checking account - automatic fines in the United States. This online banking start-up does not charge the customer a penalty fee even if he/she does not deposit a certain amount or more. It even analyzes the customer's consumption pattern and helps the customer manage the finances well by analyzing his/her consumption patterns. Currently, Simple 
has attracted more than 100,000 customers without a single store and received an investigation close to $\$ 20$ million. Now, Simple have attracted more than 100,000 customers even without one existing store, and has \$20 million investment or so.

Ondeck (ondeck.com) - Just like a bank, Ondek offers small loans to the self-employed from a very small amount to several hundred thousands of dollars. Ondek also conducts a loan review via online without a store and the review process is very fast. The reason why Ondek can proceed with the loan review that fast is that it developed the technique that can analyze the bank transactions, cash flow, and social media comments of the operator who has applied for the loan through an algorithm regarding his/her creditworthiness.

Stripe (stripe.com) - Stripe is one of start-ups that will innovate the mobile payment sector, It is not easy for the user to enter the card number and to pay the money through the smartphone screen. Stripe made it easy. Currently, Stripe has become a partner of Apple Pay with huge payment companies such as Visa and has been selected as a payment service company that allows the user to add on-line shopping functions on Twitter.

Affirm (Affirm.com) - Affirm provides a payment service that allows the user to purchase goods by installments without his/her credit card during online shopping. It lets the user him/her know via SNS whether installment purchase is available after an investigation of his/her creditworthiness in a short time using some data, such as customer credit worthiness. For example, if the user's creditworthiness turns out to be good when buying a stuff priced worth $\$ 100$, the installment will be possible only with a small fee. If the credit rating is a little low, the user will buy the stuff after paying an additional fee.

Square (square.com) - It has a system to allow you to attach a small credit reader to your smartphone to build POS. It is aimed at the street vendors who have difficulty in staring their business equipped with a credit payment system.

In the US in recent years, there is an increase in the number of the makers taking orders using a smartphone or an iPad to which a Square reader has been attached.

\section{Trends of Fin-Tech in Korea}

As the rapid growth of the fin-tech industry of the future is expected, the investment in the related industry has increased steadily in the global market. In Korea, large ICT companies are entering the payment remittance market; however, the fin-tech commercialization by fin-tech companies, such those overseas, has not existed. The reason why the fin-tech industry in Korea is sluggish in growth is that the pre-regulation by laws and the specificity of the domestic payment market environment resulting in ActiveX make it difficult to promote fin-tech projects of fin-tech companies. If the competitiveness of the fin-tech industry of Korea is not raised in the mid- to long-term, the domestic-related industry and the market are likely to be dependent on companies. Therefore, the effective fostering of the national fin-tech industry, it is necessary to allow venture capitals partly, to provide active support by the government to expand funding for related companies, and to make deregulation as done in the UK that has emerged as one of the world's emerging center of the world in fin-tech industry. In addition, it is also necessary to recognize the importance of fin-tech and to allow Korean banks as well to increase the investment in the fin-tech. But deregulation is needed to foster the domestic fin-tech industry; the control of the sector where financial stability is hindered or a large financial accident may occur need to be considered sufficiently.

Compared to the global growth of fin-tech, financial services using fin-tech in Korea is in the level in developing countries. Korea once has informed the advantages of the online world and started online payment services first in the world in early 2000 . However, Korea is now at a tottering stage, continuing to lag behind other countries.

Recently, Kakao started stock information services and stock trading services based on Kakao Talk, etc In addition, it tries to start Bank Wallet Kakao for remittance, payment 
services. However, in Korea, IT companies' expansion into financial business are strictly regulated. The finance accidents taking place recently might have acted to consider these regulations very positive. Thus, domestic IT companies' expansion into financial services may be considered to be even negligible. The status of Korean IT companies entering financial services are as follows:

\section{Potential Market of Fin-Tech}

As a proportion of cash transactions reach $85 \%$ worldwide, the credit card transaction fee market seems to be a potential market. Given that the credit card industry reaped $\$ 48.0$ billion of credit card fees last year, it is predicted that enterprises' desire for the innovation of the fees market will change a lot.

Every year about $\$ 50$ billion of credit card fees are entering into banks or credit card companies from merchants. For this huge amount of fees of money, fin-tech enterprises are bending all their energies. When you use a credit card, the card company gains 1.5 to $2.7 \%$ amount of the charge from the merchant, between the merchant and the card issuer, there is VAN (Value-Added Network), a network that helps card payment authorization and acts on behalf of the card slip. The VAN receives $10 \sim 30 \%$ of transaction fee from the merchant each credit card transaction. As such, as much as credit cards are used, the costs of the merchant will increase and the margin is bound to fall. Therefore, for the online shopping where the potential of cash payment is inevitably low, an innovative market that allows merchants to reduce the costs is waiting for us.

\section{Fin-Tech Promotion Abroad}

In promoting fin-tech, major countries such as the United States, and the United Kingdom are carefully considering environments, including their financial infrastructures and their ICT development. In the service area as well, these countries have applied fintech widely from payment to lending and reception. Due to the particularities that each country faces, the development aspects of the fin-tech industry appears differently according to differences in levels of financial infrastructures, commerce environments, and governmental policy directions. In Korea, remittance and payment are made in realtime through credit cards, internet banking systems, etc In the United States, however, much time is consumed due to national characteristics. Thus, fast and easy-to-use payment services have been developed and are actively operating.

The global fin-tech industry is led by the United States and the United Kingdom where the financial industry has developed and the venture entrepreneurship is activated. Recently, Israel, Australia, Hong Kong, Singapore, etc are also making efforts to activate the global fin-tech industry. In particular, major financial companies in the United Kingdom and the United States are making efforts to affiliate with promising fin-tech enterprises and internet banks or are pushing the acquisition of them. Britain's HSBC, First Direct, Nationwide, etc are providing more advanced financial services that enable payments by entering just a password only in partnership with Zapp, a fin-tech company.

Fin-tech enterprises abroad have entered the global market by partnering with innovative business models and ICT companies. These companies are providing convenient payment services to individual customers and businesses worldwide regardless of the differences in the local currency and billing system of each country. These companies hold their own security technology to accurately determine the customer's creditworthiness or whether a financial accident may occur or not in a short time by analyzing a variety of financial information held by financial institutions.

The representative companies include PayPal, Alipay, Apple Pay, etc (payment), Trasferwise, etc (international remittances, Ondeck, etc (online loan), and Billguard, etc (asset management such as security). 


\section{Importance of Fin-Tech Security}

As the finance and security ICT market have been receiving unprecedented media and government attention, large corporations and small businesses reported cyber breaches in the past year. This brought the estimated cost of cybersecurity breaches to the huge amount of costs or large businesses and smaller ones over the past years. In general, regulatory trends are beginning to emerge as governments begin to take countermeasures.

In particular, the financial sector is vulnerable to attacks and targeted and sustained attacks could have far-reaching economic effects for the entire economy. For this reason, cyber-security tests were carried out in several countries. For example, with more than 200 representatives from the UK's major banks, including US banks such as Citi and Bank of America Merrill Lynch with global operations in London, financial regulators took part alongside, such as the Fiscal Conduct Authority (FCA), Prudential Regulatory Authority (PRA), the UK Treasury, the Bank of England and big financial services infrastructure providers from exchanges, clearing and payment platforms. The report was published in February 2014 showed that cross-sector communications and coordination protocols were in place but that there were a number of potential vulnerabilities in the system and that financial institutions need to draw up plans for protection as a priority. The UK banking sector is at particularly high risk due to old and complex IT systems, as well as a high degree of interconnectedness and its reliance on centralized infrastructure, such as payment systems and clearing houses. Banks and organizations core to the financial system have been given six months to outline their strategies to protect themselves against potential cyber-attacks by the Bank of England's Financial Policy Committee (FPC).

For Korea, since last year, it has continued to experience large and small financial accidents, such as the privacy spilled accident from 3 card companies, POS system hacking, and the withdrawal accident of 120 million through telephone banking. The National Statistical Office survey revealed the reason why users of the online payments did not used internet payments and mobile payments in 2014. The results found that they worried about 'information leakage and security concerns' (72.3\%, 78.3\%).

It was found that as a new access channel to financial services is expanded, a concern about the loss regarding the personal information increases due to security problems such as hacking.

In overseas cases, about 0.1 billion pieces of credit and personal information were leaked from a large global fashion company 'TJX in 2007. Thus, damage occurred due to the second crime, such as identity theft, fraudulent withdrawals of accounts, credit cards fraud, etc

In 2009, 130 million pieces of financial information (card number, expiry date, etc) were hacked in a US credit card company, Heartland Payment System. and the information were leaked from the company. In a large discount store 'Target', 70 million pieces of customer information, financial information, etc were also hacked and leaked (2013). Last year, the Internet auction site 'eBay' suffered large accident over personal information hacked and leaked. In addition, Bitstamp, an exchange of a virtual currency 'Bitcoin' was hacked; the damage was estimated to be Bitcoin 19,000 (about KRW 55 million). Thus, trading was temporarily suspended. For Paypal with 100 million users all over the world, its parent company 'eBay' was attacked by hackers and thus Paypal accounts linked with eBay accounts were leaked to outside. Paypal subscribers do not need to install additional S/W to purchase products. Inputting Paypal ID/PW only allows them to make a payment without inputting their card information and their certification procedures. Some countries require an additional authentication process through mobile phone short text messages (SMS) or OTP (One Time Password). Information leakage accidents of fin-tech enterprises abroad are very serious given that the number of direct purchasers in Korea is increasing. 
More than 500 personnel dedicated to information leakage prevention are placed in 20 countries where Paypal is available. 7,000 employees in 17 centers around the world, including security and risk management human resources, are performing security duties.

To comply with PCI-DSS 12 security standards and to prevent electronic banking fraud at the same time, the company has acquired a security company (Fraud Science) and introduced a new security technology, which is mainly aimed to prevent financial accidents. Additional authentication is available during registration a mobile phone using the web standards (SSL). Illegal trade practices are being monitored using the FDS (Fraud Detection System).

A filtering system is being operated to prevent Phishing fraud since remittance and payment information is delivered to the purchaser by email.

Fin-tech is the service that requires security as a pre-requisite. It is because if security is not guaranteed, any security threat may occur in the fin-tech era. The accessibility and safety of users is like a double-edged sword, because the former should be simplified and the latter should be enhanced. Thus, convenience and security need to harmonize.

In addition, it is required to clarify the legal responsibilities to minimize the damage. But the understanding and agreement between the parties are needed. It is also necessary to enhance the security of fin-tech in order to develop the fin-tech industry and to achieve the financial innovation. The success of fin-tech is dependent on providing more simple and convenient services to the users than now using financial services, as seen in Apple Pay of the United States and Alipay of China. Alipay has provided a variety of financial services, such as deposits and withdrawals, payments, transfers, mortgages, bill payments, funds, and insurances by interacting with credit cards, bank accounts, etc Alipay is complying with the PCI-DSS security standards and is encrypting transactions and authentication data using server certificate by the certificate (VeriSign) and the web standards (128bit SSL). Since 2005, the company has introduced and operated FDS to prevent electronic financial payment accidents. The company provides OTP services based on SSL certificate and its app. In case of a payment accident, the company reimburse the member for the loss to the extent of the damage amount. However, if the member or the third party is responsible, the compensation will be exceptionally applied.

In case of meeting the reimbursement criteria, the compensation will be determined based on customer evidences. Liability will not be applied to the accidents caused by the leakage of the member's ID / PW, verification number, and identity information, system problems of the bank connected, and natural disasters including natural disasters etc

Google Wallet supports both online and offline (store) payments via electronic wallet services. It is providing additional payment services in connection with its services, such as Gmail, Google Plus etc

Web standard technologies are used. Measures for PIN numbers, real-time transaction notifications, etc have been taken, SSL encryption protocols are used during communication. At least 2,048 bits encryption is done when storing payment data, an access to the Google Wallet app is done by setting the PIN number, real-time transaction history is noticed through the app.

For a non-authorized transaction reported within 120 days from the date of the transaction, a policy for $100 \%$ of the compensation program has been established. Lost phone management is operating on line (wallet.google.com), which enables the Google Wallet app or the card to be suspended.

\section{Prospects and Implications of Fin-Tech}

After the financial crisis, the uncertainty of the financial environment is increasing and the low-growth economy and worsening profitability in the banking sector delays the development of the financial industry. Thus, the need for a new growth engine is greater in the market that can bring sustainable and mutual growth. In addition, the financial 
environment changes as SNS, ICT develop along with big data. Additionally, as financial needs are specialized and diversified, it is required to meet the needs for the new financial services from a number of customers and prosumers.

As a result, the banking sector released the financial services that can represent the current technological age on the market and has sought changes in the financial market, which will be made by one financially connected service aimed to integrate the daily lives of customers into one. In particular, the offline sales space representing the banking sector will be adapted to a new financial concept as it is combined with technological products and moves into online. In addition, IT vendors seem to increase their market share in the IT market while accelerating the online financial market impact. In particular, the online payment sector and the sector of small-sum of money remittance seems to grow rapidly to increase the efficiency of the financial market.

In line with this, now it is time that Korea also should make efforts to secure a new growth engine in the domestic financial market by allowing IT companies to enter financial business and mitigating the entry regulations for the financial industry. In addition, it seems to be needed to induce a partnership between IT companies and banks in order to ensure an early stage of the online banking platform that will be promising in the future. Additionally, it is required to allow the global trend to be applied to the domestic market to prepare for competitive fin-tech start-ups.

American financial group, Capital One is pushing sales via online only without any branch after the acquisition of a Dutch internet bank, ING Direct. In China, the fin-tech market shows an explosively growth centered around 5 private banks that Alibaba established first in China. Alipay launched in 2004, based on the huge domestic market, surpassed 300 million of the domestic market members. In addition, online P2P loans also explosively grew, increasing by about ¥680 billion in 2013 from $¥ 150$ million in 2009 . Leading to the development of the fin-tech market. However, other sectors than crowdfunding, such as big data platforms, virtual currencies, internet banks, etc are still in the beginning stage,

\section{Conclusions}

The need for a new growth engine is greater in the market that can bring sustainable and mutual growth. In addition, the financial environment changes as SNS, ICT develop along with big data. Additionally, as financial needs are specialized and diversified, it is required to meet the needs for the new financial services from a number of customers and prosumers.

In particular, the offline sales space representing the banking sector will be adapted to a new financial concept as it is combined with technological products and moves into online. In addition, IT vendors seem to increase their market share in the IT market while accelerating the online financial market impact. In particular, the online payment sector and the sector of small-sum of money remittance will continue to grow rapidly in order to increase the efficiency of the financial market.

\section{References}

[1] Financial Supervisory Service Press, "Financial groups Fraud Detection System (FDS) Advancement 1.0”, Financial Supervisory Service (FSS), (2014) December 10.

[2] Financial Security Institute, "Fraud Detection System Technology Guide", (2014) August 20.

[3] Telecommunications Technology Association, "Corresponding guide for Fraud detection and response framework", (2011) December 21.

[4] KOSCOM internal reports, "Introduced into research and report on the financial industry FDS", KOSCOM, (2015) April.

[5] Y. Lee, "Cloud Computer standardization direction of the mobile services spread", Korea information Processing Society, vol. 18, no. 5, (2011), pp. 10-19.

[6] H. Media, "The new paradigm of next generation security smart defense 2.0", HWASAN Media, (2015) Febuary. 
[7] Y. Lee, "Cloud Computer standardization direction of the mobile services spread", Korea information Processing Society, vol. 18, no. 5, (2011), pp. 10-19.

[8] H. Y. Min, "Outlier Detection Method for Mobile Banking with User Input Pattern and E-finance Transaction Pattern", Journal of Internet Computing and Services (JICS), vol. 15, no. 1, (2014) Febuary, pp. 161-163.

[9] H. Seo, "Novel Anomaly Detection Method for Proactive Prevention from a Mobile E-finance Accident with User's Input Pattern Analysis", KIISC, vol. 21, no. 4, (2011) August, pp. 51-53.

[10] G. C. Lee, "A Study on Detection and Rules for Establishing Abnormal Financial Transaction Detection System in Securities Business Circles", ASTL.

[11] C. Choo, "FPGA-Based Design of Black Scholes Financial Model for High Performance Trading", JICCE, vol. 11, no. 3, (2013), pp. 190-189.

[12] S. Y. Lee, "A Study of a Secure Mobile Agent Services Based on Grid Proxy Gateway", JICCE, vol. 6, no. 3, (2008), pp. 348-352.

[13] M. Schroeck and R. Shockley, "Analytics: The Real World Use of BigData", IBM Global Business Services, IBM Corporation, (2012).

[14] H. Zhang, "Moodog: Tracking Student Activity in Online Course Management Systems", Journal of Interactive Learning Research, vol. 21, no. 3, (2010), pp. 407-429.

[15] Accenture, 'The Every Day Bank In China' \& 'The Rise of Fintech.

[16] Management of KB Financial Group Inc, KB Knowledge Vitamin, no. 60, (2014).

\section{Authors}
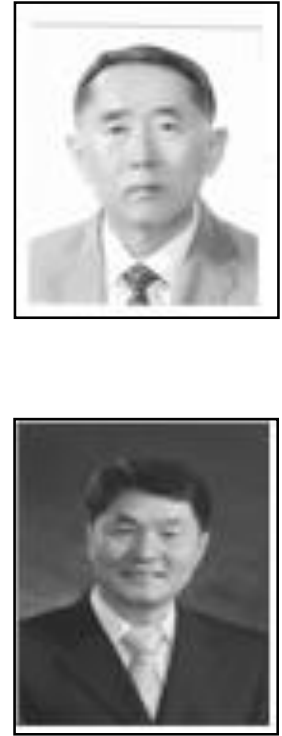

Kyeong-Seok Han received his Bachelor's Degree in Education (1979) and Master's Degree in Management (1984) in Seoul National University, Doctor's Degree in MIS in Purdue University, USA (1989). Now he is a professor in the Dept. of Management, Soongsil University, Seoul, Korea. His research interests focus on Technical MIS, Digital Economy, Agent-Eased Simulation, and Web Programming, ERP.

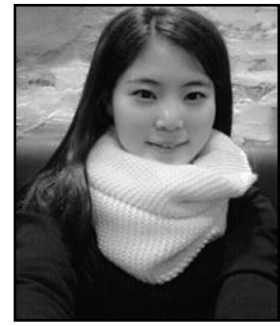

Se-Jeong Park received her Bachelor's Degree of Software Engineering in Kongju National University (2014). She is studying her Master's Degree of Software Engineering in the Graduate School of Software, Soongsil University, Seoul, Korea. Her current research interests include Database and Open Source Software.

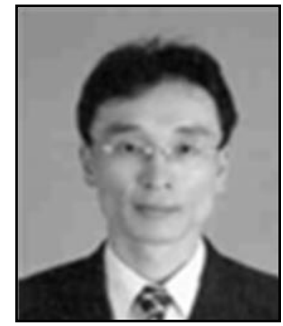

Jong-Bae Kim received his Bachelor's Degree of Business Administration in University of Seoul, Seoul(1995) and Master's Degree(2002), Doctor's Degree of Computer Science in Soongsil University, Seoul(2006). Now he is a professor in the Graduate School of Software, Soongsil University, Seoul, Korea. His research interests focus on Software. 